\title{
A Comparative Study of Evidentiality in RAs in Applied Linguistics Written by NS and Chinese Writers
}

\author{
Linxiu Yang \\ Foreign Languages School, Shanxi University, Taiyuan, China \\ Email: yanglinxiu1976@hotmail.com
}

Received August 27 th $^{\text {th }}$ 2012; revised October $22^{\text {nd }}, 2012$; accepted October $30^{\text {th }}, 2012$

\begin{abstract}
This paper is devoted to a comparative study of evidentiality in RAs (Research Articles) of NS (Native speakers) and Chinese writers. It examines whether cultural factors influence the writer's choice concerning evidentiality and the interpersonal functions of evidentiality. First, it illustrates the necessity of the comparative study. Second, it presents the findings, including the similarities and the differences. Third, the pedagogical implications are pointed out
\end{abstract}

Keywords: Evidentiality; Comparative Study; RAs

\section{Introduction}

As a pervasive linguistic phenomenon in almost all languages, evidentiality has recently been arousing the interest of linguists and has become a hot research topic in linguistics. It has been studied from various perspectives (e.g. Chafe, 1986; Palmer, 1990, 2001; Mushin, 2000, 2001; Halliday \& Matthiessen, 2004; Hu, 1994a, 1994b; Fang, 2005; Tang, 2007; Yang, 2009, 2010). Each has its own interest, purpose and research focus and sheds light on evidentiality. To further the study of evidentiality in RAs written by the writers from different cultural background, this paper makes a comparative study of evidentiality in RAs in applied linguistics written by NS and Chinese speakers. The study shows that the use of evidentiality in RAs is both universal, cultural, and language-specific.

\section{Definition of Evidentialitiy in the Current Study}

Evidentiality has become a hot research topic in linguistics. However, there has been no consensus yet on what evidentiality is and what kind of linguistic category it is. The disagreements mainly occur in the following aspects. The first is whether evidentiality is a grammatical category or a semantic one. The second is what the semantic scope of evidentiality is.

As to the issue of whether evidentiality is a grammatical category or a semantic one, studies have shown that it is language-specific. In about a quarter of the world's languages, every statement is required to specify the type of source on which it is based-for example, whether the speaker sees it, hears it, infers it from indirect evidence, or learns it from someone else. This linguistic category, whose primary meaning is information source, is called “evidentiality”. In Boas' (1938: p. 133) words, "while for us definiteness, number, and time are obligatory aspects, we find in another language location near the speaker or someone else, [and] source of informationwhether seen, heard, or inferred-as obligatory aspects."

From Boas' words, it can be seen that in some languages, evidentiality is an obligatory category. As to how to express evidentiality, different languages demonstrate different evidential systems. Tariana, an Arawak language, spoken in the multi- lingual area of the Vaupes in northeast Amazonia, has a complex evidential system. In this language, one cannot (cannot) simply say "Jose played football”. Instead, speakers have to specify whether they see the event happen, hear it, or know about it because somebody else tells them, etc. This is achieved through a set of evidential markers fused with tense. Omitting an evidential in Tariana will result in an ungrammatical and highly unnatural sentence. Look at the following examples.

a) Juse ifida di-manika-ka.

"Jose has played football (we saw it)";

b) Juse ifida di-manika-mahka.

"Jose has played football (we heard it)";

c) Juse ifida di-manika-nihka.

"Jose has played football (we infer it from visual evidence)";

d) Juse ifida di-manika-sika.

"Jose has played football (we assume this on the basis of what we already know)”.

(Adapted from Aikhenvald, 2004: p. 2).

The examples above illustrate that the evidentiality is obligatory in the language of Tariana. To mark the information source, some markers are used, such as ka, mahka, nihka and sika, which are termed as evidentials or evidential markers in evidential studies. These instances show that in Tariana evidentiality is a grammatical category and it is expressed through affixes or clitics. However, this is only one of the understandings concerning evidentiality and evidentials. If evidentiality is defined from the formal perspective, it seems that evidentiality only occurs in some languages, but is not universal. For example, in the languages of English, Chinese, German and so on, there are no grammaticalised evidential systems. In these languages, there are no affixes or clitics to express evidentiality. Thus, concerning evidentiality, there exist different research orientations. While some linguists still show great enthusiasm for describing the grammatical evidential systems of some languages, more researchers agree that evidentiality is not a grammatical form, but a semantic category. It is agreed that the semantics of evidentials are universal and exist in almost all the languages in the world. The differences exist in whether it is obligatory or optional and how the semantics are construed in grammatical, lexical or other forms. For example, Japanese pre- 
sents a quite complex system of evidential coding. It has both grammaticalised and non-grammaticalised evidentials (Mushin, 2001). Unlike Tariana and Japanese, the evidential category in English is not grammaticalised (Lazard, 2001). Yet, English has a rich repertoire of evidential devices (Chafe, 1986). It has a broad range of devices such as verbs, adverbs, adjectives, nouns and so on. According to Chafe (1986: p. 261), the difference between some Indian languages and English in evidentiality is not a matter of evidential vs. number of evidentials. It is partly a question of how evidentiality is expressed: is it by suffixes, adverbs or something else?

Studies have also shown that some linguists still stick to the grammaticalised evidentials and exclude other realization forms of evidentiality. However, more researchers tend to take evidentiality as a semantic one and study various forms in different languages. In English, if evidentiality is taken as a grammatical category, just as in some Indian languages, it appears unnecessary to study evidentiality, for there seems to be no grammaticalised evidentials. In fact, many researchers have been studying evidentiality in English (e.g. Chafe, 1986; Palmer, 1990, 2001; Mushin, 2000, 2001; Halliday \& Matthiessen, 2004; Hu, 1994a, 1994b; Fang, 2005; Tang, 2007), which shows that the notion of evidentiality as a semantic one has been broadly accepted. This paper also takes evidentiality as a semantic notion.

The previous discussion has shown that evidentiality has been accepted as a semantic notion. This has been one of the important research orientations in evidential studies. The second issue concerning evidentiality is the semantic scope of evidentiality. It is claimed (Aikhenvald, 2004) that evidentiality is an obligatory grammatical category in the language of Tariana, having the primary function of indicating the source of information. This view is considered to be the narrower understanding of evidentiality in evidential studies. Bussemann (1996: p. 157), one of the linguists who hold the narrow view on evidentiality, defines evidentiality as "the structural dimension of grammar that codifies the source of information transmitted by a speaker with the aid of various types of constructions". Aikhenvald (2003: p. 19) also overtly declares the narrow view of evidentiality. She defines the term "evidentiality" in its strict grammatical sense. She holds that the gratuitous extension of evidentiality to cover every way of expressing uncertainty, probability and one's attitude to the information is one of the current misconceptions concerning evidentiality. She thinks that this extension will be unhelpful and quite uninformative and that this approach obscures the status of evidentiality distinct from modality, mood and tense. Those who hold the narrow definition of evidentiality mainly put their focuses on some highly-inflectional languages and concentrate on the detailed descriptions of the grammatical evidential systems.

However, this is only one side of the coin. There is another understanding that with the indication of information source as the core meaning, evidentiality may also be related to the degree of the speaker's certainty of the information. Compared with the previous one, this is a broad view of evidentiality. First, it does not confine evidentiality to a grammatical one. Instead, it treats evidentiality as a semantic notion and whatever forms of evidentials are within the scope of research. Second, evidentiality, in addition to indicating the information source, may acquire other meanings of reliability, probability, possibility, etc. Third, the semantics of evidentiality is universal, and is expressed in different languages. Some languages have grammaticalised systems to indicate evidentiality, but others do not.
In some languages, evidentiality is obligatory, but in others it is not. Chafe (1986) is the leading figure who defines evidentiality in its broadest sense. He defines evidentiality as "attitude toward information”. Under the broader definitions, both grammatical evidentials and lexical ones are taken into consideration. Therefore, evidential studies are not only confined to those languages with grammatical evidential systems, but also extended to almost all the languages in the world.

In sum, in this paper we take evidentiality as a semantic notion to indicate the information source and, at the same time, the speaker's degree of commitment to the factual status of the information.

\section{Literature Review and the Necessity of a Comparative Study}

Studies of evidentiality began in the early part of the 20th century, and the leading figures are Boas (1911), Sapir (1921), and Jakobson (1957), to name just a few. The initial stage of evidential studies focused on some highly inflectional languages and more efforts were made to describe the grammaticalised evidential systems. Since then, there has been a surge of interest in the topic of evidentiality. The publishing of a collection of papers on evidentiality under the title Evidentiality: The linguistic coding of epistemology (Chafe \& Nichols, 1986) has become a milestone. Thereafter, evidentiality has been approached from different perspectives by various scholars.

Chafe (1986) studies evidentiality in a broad way and defines "evidentiality" in "the broadest sense". His definition of evidentiality concerns the speaker's attitude toward knowledge with sources of information embodied in it. He notes the reliability of evidentials, but the defect is that he does not pay enough attention to context. In his study, Chafe also shows that evidential use is one of the differences between spoken and written languages by comparing evidentiality in academic writings and conversations.

Palmer (1990, 2001) takes evidentiality as a type of modality, a sub-category of propositional modality. He treats evidential modality as a different term from epistemic modality, but he also admits the overlap between the two. He also talks about the reliability of evidence in some languages and frames the hierarchy of evidentials.

Mushin's study $(2000,2001)$ focuses more on the epistemological considerations of the evidence in presenting information. The most important point in Mushin's study is that the adoption of a particular epistemological stance in presenting information depends not only upon the source of information, but also upon the overall communicative goals, which proves that the information source sometimes does not coincide with the actual evidential choice. There are many factors which will influence the speaker's adoption of evidentials.

Aikhenvald \& Dixon (2003) and Aikhenvald (2004) treat evidentiality in its narrowest sense and pay much attention to evidential systems in different languages, especially in some less-known languages in the world. They only focus on the grammatical evidentials, and lexical ones are outside the scope of their research. In their research, they point out the relationship between evidentiality and genre convention. They also mention the pragmatic implications and effects of evidentials and point out that the irregular evidential use will bring about unexpected stylistic effects, which sheds light on the evidential study at the genre and discourse level. 
Nuyts (2001) also touches upon evidentiality in his study of epistemic modality from the cognitive-pragmatic perspective. In his study, he admits that evidentiality and epistemic modality are sometimes conflated, yet he still treats epistemic modality as a different category from evidentiality. He holds that evidentiality concerns the speaker's indication of the nature (the type and quality) of the evidence invoked for (assuming the existence of) the state of affairs expressed in the utterance, but it does not involve any explicit evaluation in terms of the truth of the state of affairs. According to his study, evidentiality can be taken as one of the qualification categories differentiating the divergent expressions of epistemic modality.

In Systemic Functional Linguistics (SFL), evidentiality is not studied as an independent category. In fact, Halliday \& Matthiessen (2004: p. 605) mention for the first time "evidentiality” in the third edition of "Introduction to Systemic Functional Linguistics". In their opinion, when "a proposition is assessed as being projected by somebody other than the speaker", "this kind of assessment is known as evidentiality". Halliday's understanding of evidentiality only concerns certain types of evidentiality, but not all the types. Although SFL does not conduct a detailed study of evidentiality, the theoretical framework can be adopted to interpret evidentiality from a functional and social perspective just as Fang (2005) and Tang (2007) have done.

In China, some scholars have studied evidentiality from different perspectives. The first type is the introduction of the linguistic phenomenon of evidentiality. The second is the application of the theories of evidentiality to analyse certain texts, such as Hu (1994a) and Tang (2007). Fang (2005, 2006) talks about the nature of evidentiality from the perspective of SFL and points out that the study of evidentiality in SFL can elevate the evidential studies up to a metatheoretical level. Zhu (2006) devotes much to the Chinese evidentials and shows the unique expressions of the semantics of evidentiality in Chinese. Tang (2007) discusses the discoursal features of evidentiality in English news reports of an epidemic situation update. These researches have been of great help for people to better understand the linguistic phenomenon of evidentiality from wide perspectives.

In spite of the achievements made in the previous studies on evidentiality, research in this area is still in its infancy and much work still needs to be done for improvement and supplement. For instance, the study of the evidential use in academic discourse is far from enough. More comparative study between different cultures is needed. In particular, the necessity of the comparative study lies in the following two points:

First, the comparative study is theoretically significant. Through the comparative study of evidentiality in RAs in applied linguistics produced by NS and Chinese writers, the study seeks to show that evidentials chosen by the RA writer will be influenced and bounded by cultural characteristics. The study reveals that while the semantics of evidentiality is universal, evidentials the speaker/writer chooses in the same genre or context may be different. The differences may be attributed to cultural differences, to some degree, if not all. Therefore, this study, in theory, will show that evidential uses in the genre of RAs are culturally bounded.

Second, the comparative study is pedagogically significant. RAs are perhaps one of the academic genres that have attracted the greatest attention, not only because of the vast number of articles published annually, but also because of the need to help the researchers and postgraduate students to succeed in the construction of texts appropriate for submission of scientific journals. Much of the success involves academic socialization, that is, an understanding of the rules and strategies of the academic community (Belcher \& Braine, 1995; Swales, 1990), which is materialized in the linguistic choices made in the texts. Unfortunately, these linguistic choices do not appear to be clear to the non-native and novice writers of RAs in English. Particularly in the foreign language contexts, the researchers often suffer from the reiterated frustration of having their papers returned for language reasons. For non-native writers, they need to know not only the cultural and rhetorical aspects of writing an article but also the use of grammar and lexis to construct sentences appropriate for the RA.

The current research holds that evidentiality is a strong discourse strategy to fulfill the various interpersonal functions. However, it does not stop at the semantic level. Instead, it goes further to examine the grammar and lexis to realize the semantics of different evidential strategies. The latter one is more pedagogically significant. The functional grammar (Halliday, 1994, 2004), which relates form to meaning and context, is the basis of this research to relate the semantics and functions of evidentiality with linguistic forms. From the detailed quantitative analysis of the corpora, the study finds the specific differences of evidentiality used by NS and Chinese RA writers. Therefore, the help for non-native writers is more practical. In this regard, this comparative study is mainly pedagogically significant and it will help the Chinese writer to step toward success in publication in English.

In sum, the comparative study aims to examine whether the cultural factors will influence evidential adoptions in RAs. It tries to raise the RA writer's awareness of how evidentiality can help the writer in the construction and attainment of persuasion.

\section{Data and Methodology}

English RAs of applied linguistics are chosen as the data. In spite of disciplinary differences as an influencing factor, the exploration of evidential use in different disciplines is beyond the scope of the current study. The corpus consists of 100 RAs in applied linguistics amounting to about 670,000 words. For the comparative study, 50 RAs published by NS writers and 50 produced by Chinese writers are selected. The articles come from the Internet (www.elsevier.com) and the journals in the libraries of Xiamen University. The English journals selected for this study are: Journal of English for Academic Purposes (2004-2008), Journal of English for Specific Purposes (20042008), and Journal of Pragmatics (2004-2008) (see Appendix 1). The data of RAs are confined to the same period because of the fact that genres are quite stable in a certain period of time. On the other hand, they are also in a state of constant evolution, as Fairclough (1992) notes, "a genre implies not only a particular text type, but also particular processes of producing, distributing and consuming text... Changes in social practice are both manifested on the plane of language in changes in the system of genre, and in part brought about by such changes". The genre of RAs also may change over time. Therefore, in order to examine the linguistic features of RAs, the study chooses RAs published during the same time for the validity of the research results. The 50 RAs produced by Chinese writers in applied linguistics come from the journal Teaching English in China from 2004 to 2007. 
The data-coding of this research is done manually at the preliminary stage to identify and count all the potential lexical and discourse-based items that indicate different evidential types. The material for data-coding includes the body of the articles, i.e. the complete text of the articles, excluding abstracts, notes, linguistic examples, tables, and figures. Then, Microsoft Office Excel is adopted to deal with the data and draw the figures accordingly. In addition, in order to take the context of evidentials into consideration to find the concordance patterns, a concordance software is also adopted. This quantitative approach is meant to identify the frequency of occurrences and to produce comparable data. The statistical results are the basis for later illustration of evidentiality as a discourse strategy to fulfill the various interpersonal functions. The frequency of occurrence of each group of items is calculated in permillage (This passage should use the past tense).

\section{Findings of the Comparative Study}

The quantitative results reveal some similarities and differences between the two (specify what two things explicitly here). In this part, the similarities and differences are elaborated, from which the common characteristics and different academic conventions concerning evidentiality can be clearly shown.

\section{Similarities Found in the Comparative Study}

After the close examination in the comparative study, the similarities are summarized as follows.

First, the semantics of evidentiality is universal in both of the two corpora. Look at the Figure 1.

As is shown in Figure 1, the writers in both corpora use a significant number of evidentials ( $\mathrm{f}=11.83$ for $\mathrm{NS}$ and $\mathrm{f}=$ 10.54 for Chinese), which shows that evidentiality is a pervasive linguistic phenomenon in RAs, with no significance between the two groups of writers. It also shows the universality of the semantics of evidentiality in RAs across languages. In both the corpora, the writer adopts various evidential types and also respective linguistic forms to show how he or she acquires the information and in what degrees he or she makes commitment to the factual status of the information. All the evidential types in our classifications occur in both of the corpora. One more common characteristic is that in both corpora, there is an unbalanced adoption among different evidential types. The most frequently used evidentials are reporting evidentials and

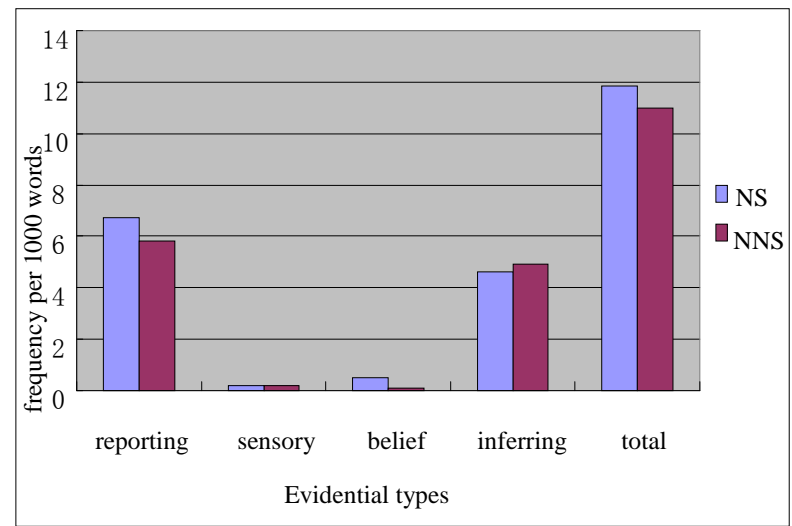

Figure 1.

Frequencies of evidential types in NS and Chinese corpora. inferring evidentials. Belief evidentials and sensory evidentials are less common in both corpora. This unbalanced adoption tendency reveals the typical way in which the RA writer constructs knowledge.

Second, the interdependent relationship between the generic structures and evidential types exist in both of the corpora. Consider the Tables 1-3 and Figure 2.

For a clearer picture, Table 1 can be diagrammed as follows.

Table 1 and Figure 2 show that in different generic structures evidential types occur with different frequencies. For instance, Introduction adopts the most evidentials and Data and Method the least, with Findings and Discussion part and Conclusion part in the middle. It is also found that certain generic structures demand certain types of evidential types and certain types of evidentials prefer certain generic structures. For example, other-reporting evidentials are mainly adopted in the introduction, while the inferring evidential strategy is adopted in the

Table 1.

Evidential types and generic structures of RAs in the two corpora (with frequency per 1000 words).

\begin{tabular}{|c|c|c|c|c|c|c|c|c|c|}
\hline & \multicolumn{4}{|c|}{ Other-reporting Self-reporting } & \multicolumn{2}{|c|}{ Belief } & \multicolumn{2}{|c|}{ Sensory } & Inferring \\
\hline & NS & NNS & NS & NNS & NS & NNs & NS & NNS & NS NNS \\
\hline Introduction & 9.65 & 8.50 & 2.16 & 1.08 & 0.32 & 0 & 0 & 0 & 3.093 .45 \\
\hline $\begin{array}{l}\text { Data and } \\
\text { method }\end{array}$ & 1.87 & 1.80 & 0.54 & 0.44 & 0.07 & 0 & 0 & 0 & 1.951 .87 \\
\hline $\begin{array}{l}\text { Findings and } \\
\text { discussion }\end{array}$ & 3.08 & 2.98 & 2.07 & 1.98 & 0.344 & 0.01 & 0.27 & 0.34 & 4.444 .64 \\
\hline Conclusion & 1.87 & 1.90 & 3.57 & 3.45 & 1.33 & 0.02 & 0 & 0 & 7.676 .86 \\
\hline
\end{tabular}

Table 2.

Realizations of evidential types in NS and Chinese corpora.

\begin{tabular}{cccc}
\hline \multirow{2}{*}{ Evidential types } & Evidentials & \multicolumn{2}{c}{ Frequencies } \\
\cline { 3 - 4 } Sensory & See & NS & NNS \\
\hline Belief & $\begin{array}{c}\text { I/we suggest, argue, think; it } \\
\text { can be suggested, argued, } \\
\text { assumed, etc. }\end{array}$ & 0.17 & 0.15 \\
Reporting & $\begin{array}{c}\text { Author + date } \\
\text { Verbal }\end{array}$ & 2.06 & 0.24 \\
& Non-verbal & 2.18 & 2.13 \\
& Modal verbs & 0.38 & 0.29 \\
& Relational process & 1.07 & 0.97 \\
Inferring & Adjectives & 0.33 & 0.37 \\
& Modal adjunct & 0.08 & 0.97 \\
\hline
\end{tabular}

Table 3.

Reporting verbs used in NS and Chinese corpora.

\begin{tabular}{cc}
\hline & Frequently adopted other-reporting verbs \\
\hline NS & Find, argue, point out, suggest, claim, show, assume, think, \\
hold, note, reveal, observe, indicate \\
Chinese & Claim, find, note, indicate, argue \\
\hline
\end{tabular}




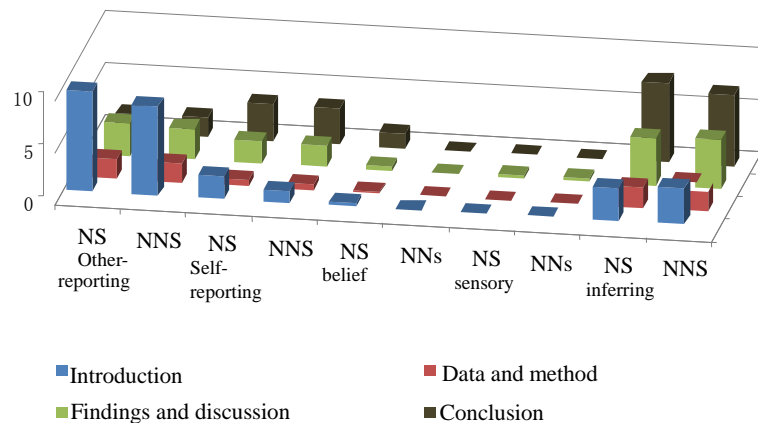

Figure 2.

Evidential types in generic structures of RAs by NS and Chinese writers.

Discussion and Conclusion parts. The infrequently used evidential strategies only occur in certain generic structures. For example, the sensory evidentials are only used in the Findings and Discussion parts. This close relationship between the generic structures and evidential types reveals that the sub-purposes and nature of different generic structures will affect the writer's adoption of evidential types.

Third, the linguistic realizations of evidentiality bear the similar characteristics in both of the corpora, as shown in the following table.

As seen from Table 2, verbal forms are the most frequent realization of evidentiality in both corpora except the author + date convention. As for the inferring evidential type, the frequently used form is the modal verb and as for the reporting evidential type, reporting verbs are most often used.

Fourth, in both of the corpora, evidentiality can be taken as a discourse strategy to realize the interpersonal functions discussed in the current research. This means that evidentiality is not just a means to denote the information, but more importantly, it is a rhetorical device. It has more functions than indicating information source. The writer's evidential choice will have interpersonal and discourse implications, and in turn, the negotiation of the interpersonal relationship is one of the important motivations for evidential choice. This is the common characteristic of evidentiality in RAs with no difference across cultures.

In sum, the similarities in evidential use in RAs of NS and Chinese writers show the universality of semantics of evidentiality in RAs. The writer adopts different evidentials to denote the construction of knowledge in different generic structures of RAs. Evidentiality can help the writer do more than indicating the information source.

\section{Differences Found in the Comparative Study}

In addition to the similarities, differences concerning evidentiality as a discourse strategy to fulfill the interpersonal functions are summarized as follows.

First, differences exist in the use of reporting evidential type. Figure 1 has shown that reporting evidential type is the most important evidential type in both of the corpora. However, the difference lies in the degree of the writer's awareness of adopting this evidential type to fulfill the interpersonal functions discussed in the previous sections. As has been mentioned, when reporting the prior work and other researchers' work, the writer will at the same time show his evaluation of and stance toward the reported sources and the reported information. The choice of reporting verbs reveals the writer's stance. Reporting verbs can be used to represent the reported information as true or as false. The verbs also allow the writer to ascribe a view to the reported authors as positive, neutral, tentative or critical. However, the study has found the differences in the two corpora concerning the reporting of evidential type. Look at the Table 3.

As seen in Table 3, there are some differences in reporting verb choice. Compared with the Chinese writer, the NS writer has more choices in reporting verbs. They can choose from more different reporting verbs to select the most appropriate one. It is unclear whether the language proficiency may cause the NS writer to choose within a broader range, but it seems to be certain that the Chinese writer may not have clear awareness of the discursive implications and the interpersonal functions of the reporting verbs. Sometimes, what they need is just to find a verb and they seem not to consider whether this verb will help them to get a certain discourse or interpersonal purposes. It is also found that the Chinese writer more frequently chooses reporting verbs such as claim, which is one of the important means for distancing from a dialogic perspective as discussed above. By using this type of reporting verb, the writer will leave limited room for the reader to join in the dialogue and admit little dialogistic space for alternative viewpoints. Therefore, it can be concluded that, although the NS and Chinese writer both admit the importance of the prior literature and show significant respect for previous research, the Chinese writer seems to have less power in choosing appropriate reporting verbs to help him or her to fulfill the interpersonal functions. He is much more inclined to impose attitudes towards the previous work upon his reader. The writer's authorial identity is unreasonably exaggerated.

In addition to the differences in the choice of reporting verbs, it is also found that in choosing the information source, differences also exist. As stated above, to report others' work, the writer can choose between human and inhuman sources, or between specific and unspecific. In this regard, it is found that the specific human source, such as Hyland argues that... is common in both the corpora. Compared with the NS writers, the Chinese writer adopts more unspecific sources for the otherreporting type. For example:

1) Some suggest that CALL aids language teaching and learning, at least in terms of the improvement in computer literacy, or that students feel good merely because they are using computers.

2) Many believed that CALL aids language teaching and learning in terms of increased motivation, interest and authomony; some even suggest that the adoption of CALL has some positive effects on the improvement of students overall performance.

The two examples above show that the writers choose an unnamed source to formulate a generation from the relative literature reading. This unnamed source is occasionally used by the RA writer for generalization, but, too often, adoption is similar to the bald statement of a generalization (Barton, 1993). The ideas become less academic because they are not attributed to a scholarly and specific source They are too general because they are attributed to a generalized source. The NS writer, however, does not reward this strategy of generalizing source material.

Second, differences in the use of self-mention as the information source exist in the two corpora. As mentioned above, 
the writer sometimes adopts self-mention such as $I$, we, our study, and so on as the information sources. Self-mention is a common rhetorical strategy for the construction of academic persona. This authoritative persona can be maintained by the adoption of belief evidentials and self-reporting evidentials, which have been discussed in the previous sections. However, some differences are found between the NS and Chinese writer in this regard. According to our data survey, the Chinese writer, compared with his NS counterpart, is more likely to adopt exclusive we rather than $I$ for self-mention, although their papers are not co-authored. This strategy is a means to lessen the authorial visibility and functions as a self-protecting way to present the writers' belief and opinions which makes the writer more distanced from the information. This tendency for the Chinese writer to prefer we to $I$ has the negative effect of lessening the authoritative persona of the writer.

Third, as mentioned above, in the use of inferring evidential type, the writer tends to choose low value of modality to show lower degrees of certainty. This hedging strategy has rhetorical functions. For instance, it can lessen the writer's responsibility for the truth and factual condition of the information or it can broaden the dialogic space to allow for alternative positions from the reader, or it is a politeness strategy to avoid the face-threatening acts to both the writer and to the reader, and so on. For whatever reasons, choosing a low degree of certainty to present information is more often used by the writer than to choosing a higher degree of certainty by using the modal must. However, our examination has shown that the Chinese writer tends to use a high degree of certainty more often than the NS writer. This has the negative effect because the information will sound too imposing for the reader to accept.

\section{Conclusion}

Through the examination of evidentiality used in RAs by NS and Chinese writers, the study shows that, in RAs by the writers from different cultural backgrounds, the evidential use patterns share both similarities and differences. The similarities show the universality of the semantics of evidentiality in RAs. The differences show that in expressing evidentiality, the writers from different cultural backgrounds and with different language proficiencies have distinct tendencies and preferences.

It is hoped that this study will be helpful for EAP courses and academic writing. The researchers' need to publish in English has generated a growing demand for academic writing courses. To satisfy this need, it is necessary to develop awareness of the different linguistic resources used by the writers who succeed in publishing. While experienced writers may understand that writing is a context-rich, situational and constructive act, many learners see reading and writing as merely an information-exchange process. Thus, to help students to move beyond this simple, ideational view to a more complex, interpersonal model should be a teaching priority. Unfortunately, the teaching practices of RAs seemed to be based on traditional normative principles rather than on solid empirical evidence from analysis of actual language use. In this sense, the current research provides some solid empirical evidence on the writer's adoption of evidentiality and the findings may have implications for the teaching of academic writing as well as deepening and broadening the writer's understanding of evidentiality in academic discourse.

In sum, writing with awareness of the relationship between evidentiality and its functions may enable the writer to construct the appropriate text in terms of evidentiality, and eventually lead to the ultimate goal of successful publication. It is suggested that in future EAP teaching and writing, raising awareness of the functions of evidential choice is the most important. The writer needs to be aware that each of his choices of evidentiality will have different discursive implications and will help them to achieve their ultimate goal more easily. The genrebased pedagogy concerning evidentiality is also necessary. Learning from the published writings will be very helpful for the students to improve their own writings.

This comparative study lays a foundation for future research and provides an orientation for further study. There are more areas to be further studied. First, the functions of evidentiality can be studied; Second, because of the genre convention, evidential use in other genres, even evidential use across genres, is worthy of more research; Third, evidential use in different languages may vary, which is believed to be an interesting topic in evidential study.

\section{Acknowledgements}

This work was supported by Chinese Educational Bureau [grant number: 11YJC740128] and Social Science Grant by Shanxi Province [grant number: 1005123].

\section{REFERENCES}

Aikhenvald, A. (2004). Evidentiality. Oxford: Oxford University.

Aikhenvald, A., \& Dixon, R. (2003). Studies in evidentiality. Amsterdam: John Benjamins Publishing Company.

Barton, E. L. (1993). Evidentials, argumentations, and epietemological stance. College English, 55, 745-769. doi:org/10.2307/378428

Boas, F. (1911). Handbook of American Indian Languages. Washington DC: Government Printing Office.

Boas, F. (1938). Language. In F. Boas (Ed.), General anthropology. Boston: D.C. Heath and Company.

Bussmann, H. (1996) Routledge dictionary of language and linguistics. London: Routledge.

Chafe, W. (1986). Evidentiality in English conversation and academic writing. In W. Chafe, \& J. Nichols (Eds.), Evidentiality: The linguistic coding of epistemology. Norwood, NJ: Ablex.

Chafe, W., \& Nichols, J. (1986). Evidentiality: The linguistic coding of epistemology. Norwood, NJ: Ablex.

Fairclough, N. (1992). Discourse and social change. Cambridge: Polity Press.

Fang, H. M. (2005). A Systemic-functional approach to evidentiality. Ph.D. Thesis, Shanghai: Fudan University.

Halliday, M. A. K. (1985). An introduction to functional grammar. London: Arnold.

Halliday, M. A. K. (1993). The construction of knowledge and value in the grammar of scientific discourse: Charles Darwin's the origin of the species. In M. A. K. Halliday, \& J. R. Martin (Eds.), Writing science. Literacy and discursive power. London: The Falmer Press.

Halliday, M. A. K., \& Matthiessen, C. M. I. (2004). An introduction to functional grammar. London: Arnold.

Hu, Z. L. (1994a). Evidentiality, reporting and argumentation. Foreign Languages Studies, 2, 22-28.

$\mathrm{Hu}, \mathrm{Z}$. L. (1994b). Evidentiality in language. Foreign Languages Teaching and Studies, 1, 9-15.

Jakobson, R. (1957). Shifters, verbal categories, and the Russian verb. Massachusetts: Harvard University Press.

Lazard, G. (2001). On the grammaticalization of evidentiality. Journal of Pragmatics, 33, 358-368. doi:10.1016/S0378-2166(00)00008-4

Mushin, I. (2001). Evidentiality and epistemological stance: Narrative retelling. Amsterstam: John Benjamins Publishing Company.

Mushin, I. (2000). Evidentiality and deixis in narrative retelling. Journal 


\section{X. YANG}

of Pragmatics, 32, 927-957. doi:10.1016/S0378-2166(99)00085-5

Nuyts, J. (2001). Epistemic modality, language and conceptualization: A cognitive-pragmatic perspective. Amsterdam: John Benjamins Publishing Company.

Palmer, F. (1990). Modality and the English modals. London: Longman. Palmer, F. (1986). Mood and modalit. Cambridge: Cambridge University Press.

Sapir, E. (1921). Language: An introduction to the study of speech. New York: Harcourt, Brace and Co.

Swales, J. (1990). Genre Analysis: English in academic and research setting. Cambridge: Cambridge University Press.

Tang, B. (2007). Systemic-functional approach to discourse features of evidentiality in English News reports of epidemic situation update. Ph.D. Thesis, Shanghai: Fudan University.

Yang, L. X. (2009). Evidentiality in English research articles. Ph.D. Thesis, Xiamen: Xiamen University.

Yang, L. X. (2010). Genre perspective on evidentiality. In Chellenges to Systemic Functional Linguistics: Theory and Practice. Sydney: Macquarie University Press. 